\title{
ASSESSING THE VALUE OF ACTION RESEARCH: USING A WORLD CAFÉ TO EXPLORE THE PROFESSIONAL JOURNEY OF NURSE EDUCATORS
}

\author{
A. van Wyngaarden* \\ Department Quality Assurance \\ e-mail: annavwyngaarden@hotmail.com

\section{R. Leech*} \\ Faculty of Health Sciences \\ e-mail: ronell.leech@up.ac.za
}

\section{M. Coetzee*}

Faculty of Health Sciences

e-mail: isabel.coetzee@up.ac.za

*University of Pretoria

Pretoria, South Africa

\section{ABSTRACT}

In developing student nurses' clinical reasoning skills, nurse educators play an important part. To promote clinical reasoning skills, nurse educators should identify and utilise appropriate studentcentred teaching and learning practices. We used the World Café data collection method to explore nurse educators' professional journey through action research. We describe how action research, participating in the study and collaborative inquiry changed teaching practices. Action research contributed to nurse educators' professional development, allowing them to reflect on own practices and develop critical thinking and clinical reasoning skills. Nurse educators reported using more student-centred teaching and learning practices. We describe the World Café method, which we used to collect data. The method can also be used in nursing education as a teaching strategy, students can explore various topics of interest whilst developing competencies in communication, building relationships and collaborative learning.

Keywords: action research, clinical reasoning, collaborative inquiry, collaborative learning, nursing education, teaching practice, World Café method

\section{INTRODUCTION AND BACKGROUND}

Teaching student nurses' critical thinking and the ability to apply clinical reasoning skills remains a challenge in nursing education (Bland et al. 2009, 14; Shellenbarger and Robb 2015, 79) and therefore nurse educators should identify and utilise student-centred teaching and 
learning practices (Chilemba and Bruce 2015, e55; Ellis 2016, 66). Conventional teaching practices encourages the regurgitation and memorisation of content where students are passive receivers of information at the expense of critical thinking and clinical reasoning. As a result, students are unable to apply knowledge to different situations (Chabeli 2010, 2). Furthermore, teacher-centred practices fail to engage and stimulate students (Shellenbarger and Robb 2015, 80).

Although nurse educators are encouraged to use more interactive, student-centred adult teaching practices, many nurse educators do not know about appropriate practices or have the skills to effectively implement these teaching practices (McKee and Billman 2011,21). To meet the need for student-centred teaching practices, nurse educators have to acquire new teaching skills such as team building, facilitation skills, group facilitation, group management and effective questioning techniques to enhance a holistic teaching and learning experience (Fahlberg et al. 2014, 92). Active learning is encouraged through the utilisation of studentcentred teaching practices where nurse educators facilitate the process and guide the learning experience (Slavich and Zimbardo 2012, 573).

Within institutions, transitions from teacher-centred to student-centred teaching and learning practices need to be carefully managed and clearly defined. In the nursing education institution where this study took place, we realised that the current, predominant teacherfocused teaching practices were not promoting clinical reasoning skills of student nurses. We identified an urgent need to implement student-centred teaching and learning practices. To facilitate the transition from teacher-to student-centred teaching, we had to consider how to improve existing teaching practices to promote the development of student nurses' clinical reasoning skills. Students who are unable to think critically, would be unable to apply and adapt their knowledge in clinical settings (Chilemba and Bruce 2015, e59; Shellenbarger and Robb $2015,79)$. We conducted an action research study with a core group of nurse educators to identify areas of improvement that would tangibly improve the clinical reasoning skills of student nurses. Action research, provided nurse educators with an opportunity to reflect on and evaluate their own teaching practices resulting in the generation of individual theories of practice. Following the action research study, we used a World Café approach to describe the value of the action research study for the nurse educators and how their teaching practices changed as a result of participating in study. We describe the World Café data collection method and how we used this method to explore nurse educators' professional journey through action research.

The nursing education institution in question was challenged to develop teaching and learning practices that would emphasise critical thinking and clinical reasoning skills. The 
concern was that if nurse educators predominantly utilise conventional teaching practices which fail to enhance clinical reasoning, the students fail at analytical application of knowledge gained (Chilemba and Bruce 2015, e59; Shellenbarger and Robb 2015, 79).

After an explanation of the methodology utilised for this study the World Café data collection method is described, including a report on how the method was implemented in this study. Furthermore, a discussion of the findings is outlined and the nurse educators journey through action research is summarised.

\section{METHODOLOGY}

\section{Design}

We conducted a descriptive, qualitative study using an action research methodology. Data were collected from the action research group participants by means of the World Café method. Both the World Café and action research method share the principles of participation and collaboration, and thus complement each other.

\section{Setting, participants and methods}

Approval of the study was granted by the Research Ethics Committee of the Faculty of Health Sciences of the University of Pretoria (protocol number: 84/2015) and the principal of the nursing education institution gave permission to conduct the research. We conducted the study at a nursing education institution in South Africa.

We invited ten participants to attend the World Café. Of these, eight members (including the first author) attended. Participants were encouraged to actively participate in the World Cafe and their consent was obtained prior to the data collection process. Data collection methods included audio recordings and photography of drawings and flip charts. The said data were creatively analysed by employing the hermeneutic perspective (Boomer and McCormack 2010, 644). In order to make meaning of the data collected, paintings, pictures, flip charts and words were used to analyse the data. In addition, the World Café method allowed participants to check and validate the data. The participants and I (the first author), identified themes and categories in the data, using the World Café data collection method.

\section{THE WORLD CAFÉ METHOD}

The World Café is a participative research method where participants are invited to become involved in the process; in understanding and answering the questions (Bradbury 2015, 212). Furthermore, the World Café method allows for collaborative inquiry between participants, 
which produces rich data suitable for action research (Bradbury 2015, 212). The World Café method creates a relaxed atmosphere, which provides group participants with an opportunity to have conversations with each other and encourages openness and honesty in evaluating the relevance to the larger action research study (Van Wyngaarden 2017, 219). The World Café method is underpinned by the following quote by the founder, Juanita Brown (Brown and Isaacs $2005,5)$ "There is nothing more powerful than a community engaged in conversation in relation to what it cares about".

In the 1990s, Brown and Isaacs developed the World Café approach (Farr 2013, para. 2), to innovatively capture discussions and conversations (Brown and Isaacs 2005, 3-4). The World-Café method has been described as "an innovative approach to facilitate large group conversations around a topic of mutual interest with the intention of collecting knowledge and information through discussion, conversations and shared listening" (Farr 2013, para. 2; Partridge 2015, para. 2). The World Café allows for groups of all sizes to engage in conversation on topics of mutual interest in a relaxed setting and is seen as a simple yet powerful conversational and brainstorming tool. Furthermore, the World Café method contributes to personal relationship building and promotes collaborative learning (Tan and Brown 2005, 83) and is best employed when dealing with topics that require combined wisdom and discussion (Chang and Chen 2015, 1284). Finally, according to Dawkins and Solomons (2017, 639), the World-Café method contributes to the development of communication, relationship building and strategic planning skills.

The name World Café compares the world to a café - a relaxing atmosphere in which issues can be discussed freely, ideas and opinions shared and where participants can simply listen to others (Jorgensen and Steier 2013, 6). The setting is purposefully made up with café styled table settings with checkered table cloths and a centre piece, coffee and soft music in the background to imitate a café style atmosphere (Fouché and Light 2010, 7; Bradbury 2015, 214; Froneman, Du Plessis and Koen 2016, 3). The World Café method creates a non-judgemental, safe, comfortable and conversational environment (Partridge 2015, para. 10) in which participants are encouraged to contribute equally and actively (Farr 2013, para. 3).

The World Café requires four to six participants sitting around a table facing each other so that they are able to participate equally to the conversation or respond to the questions posed (World Café 2008 cited in Preller et al. 2014, 6; Jordaan 2016,12). Each table has a "table host", who hosts the same table throughout the process (Brown and Isaacs 2005, 4). The table host poses a specific question to the participants, who are then given 20 minutes to respond and debate collaboratively (Jorgensen and Steier 2013, 7). Participants then rotate to the next table, where they are asked another question. The table hosts share the responses of the previous group 
with the participants to provide context (Preller et al. 2014, 7). Previous research conducted by Brown and Isaacs $(2005,4)$ advocate for three conversation rounds lasting 20 minutes each. This is followed by the table host providing feedback on the findings to the whole World Café group (Brown and Isaacs 2005, 4). Therefore, providing participants with opportunities for further engagement and understanding leading to knowledge development and collaborative learning.

The World Café integrates seven principles: set the context, create a hospitable space, explore questions that matter, encourage everyone's contribution, cross-pollinate and connect diverse perspectives, listen together for patterns and insights, finally, share collective discoveries (Fouché and Light 2010, 8; Gilson 2015, 68; World Café 2016; Jordaan 2016, 13; Jorgensen and Steier 2013, 7).

\section{THE WORLD CAFÉ METHOD FOR THE CURRENT STUDY}

We adopted a World Café approach in this study and conducted the World Café in four phases; the Preparation phase, the Opening phase, the Implementation phase and the Closing phase.

\section{Preparation phase}

During the preparation phase, we set the context for the study, which is the first principle of the World Café. We defined the aim and limits of the World Café, by introducing the relevant roleplayers to the discussion and selected relevant topics (Fouche and Light 2010, 8; World Café 2016). For this study, the World Café aimed to evaluate the "worth of an action research study". The action research group participants, and three hosts formed part of the conversation.

We invited all suitable participants to the World Café. We employed the café style theme throughout the World Café process, from the invitation to the setting as well as the refreshments. Two tables were purposely placed in the centre of the venue (view photo 1).
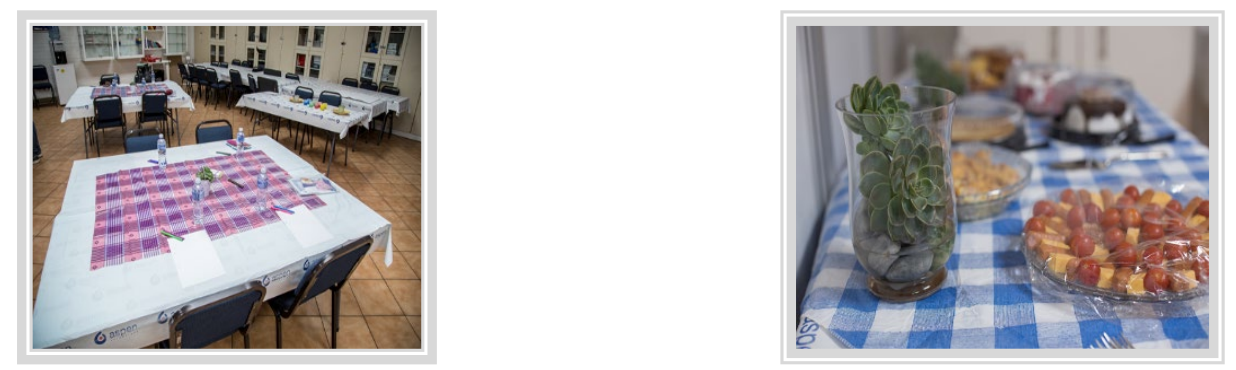

Photo 1: The venue used for the World Café. Tables were decorated and arranged in café style. Refreshments were offered. (Photos taken with consent of the participants) 
We adhered to the second principle by creating a hospitable space. We aimed to create an inviting setting with a welcoming atmosphere, where participants felt able to share ideas in a non-threatening environment, thus encouraging creativity (Stöckigt, Teut and Witt 2013, 2). Participants who feel comfortable and relaxed may become more creative in their thinking, speaking and listening abilities (Fouche and Light 2010, 8; World Café 2016). To create a relaxed café-style atmosphere, refreshments and coffee was served. The mood was accentuated by soothing background music. The relaxed dress code further contributed to the ambience. Participants were provided with the stationary required to complete the intended activities. The principle of creating a hospitable space embraces disputes and could be one of the advantages of using this method for collecting data.

\section{Opening phase}

Participants were welcomed by the facilitator who emphasised the aim of the workshop, which was to evaluate the relevance of the action research study. Permission was sought from the participants to take photographs and audio recordings during the workshop and permission was obtained to use the photographs, this process was concluded by obtaining informed consent from all participants. The facilitator outlined the sequence of events for the morning and provided a detailed description of the planned activities so that the participants knew what to expect. The workshop consisted of three sessions, each made up of an activity. Each activity formed part of the overall aim to evaluate the "worth" of the action research study. All members accepted the ground rules or "café etiquette".

To address the third integrated principle, namely, explore questions that matter, we formulated a set of questions that were interesting, open-ended, intentional and well defined (Fouche and Light 2010, 8; World Café 2016; Gilson 2015, 68). A well-defined set of questions are likely to encourage participants to share ideas and participate in the conversation. All the group members participated in the action research study and were able to yield the best answers to the question of whether or not the action research study was relevant or added any value to their lives. The following two questions were explored (Van Wyngaarden 2017, 221).

- What was the "worth" of the action research study, personally and professionally?

- How did the action research study change your teaching practices?

\section{Implementation phase}

The three activities were introduced and explained by the facilitator. To answer the two main 
questions, to evaluate the "worth" of the larger action research study, each activity built on the previous one.

\section{Activity 1: Questions}

In general, people want to feel that they have contributed and actively participated in making a difference. In our study, the host made a conscious effort to ensure that all participants had an opportunity to respond, share ideas and attentively listen to all participants (Fouche and Light 2010, 8; World Café 2016). Each of the two tables was assigned a specific question that the participants were requested to individually reflect on and then share their thoughts with each other. In so doing, we met the fourth principle, namely encourage everyone's contribution. The participants then switched tables to address the second question. However, this time the input from the previous group was shared by the table host to allow for cross pollination, the fifth principle. The findings were recorded on flip charts and displayed for discussion by the larger group later.

\section{Activity 2: Drawings}

Participants were briefed on activity 2 by the facilitator. They were requested to draw a picture that visually depicted the relevance of the action research study stressing that active participation was a critical factor for a successful outcome. Participants used the findings gathered during activity 1 to assist them with activity 2 . Participants had 40 minutes to execute this task and were provided with an array of stationary to record and depict their thoughts. Again, these were displayed to be discussed later. Each group was given an opportunity to discuss their drawing while the other group was asked to reflect on the following: "I feel", "I hear" and "I imagine" with regard to the presenting group's drawing. Following the presentations, all the participants shared their thoughts. Listening forms, a key part of the World Café method and participants are encouraged to listen to each other during the conversation rounds, thus employing "shared listening" (World Café 2016). Listening allows us to make associations and explore underlying ideas because by listening we pay attention to what is said and with each conversation themes, patterns and insights, emerge (Bradbury 2015, 212; Fouche and Light 2010, 8; World Café 2016). Listen together for patterns and insights is the sixth principle.

\section{Activity 3: Words}

The last phase of the World Café is known as the "harvest" phase and involves sharing the information or knowledge with the whole World Café group (World Café 2016; Jordaan 2016, 
13). At the end, the host is responsible for presenting the shared ideas and perceptions with the whole group. Participants had an opportunity to silently reflect on the findings, that emerged during activity 1 before sharing individual group findings with the larger group. All participants were thus involved in the data gathering process (Roos and Du Toit 2014, 7). The two groups were requested to identify statements and words which best described the relevance of the action research by utilising the findings from activity 1 and 2. Participants were given an opportunity to reflect silently and record the words that came to mind these were then shared with their table group. Each group was then asked to reach consensus on the statements or words they felt summarised the experience for them. Each table host then recorded the words on strips of paper which was later shared with the larger group. Themes and categories emerged by packing the words on the floor, shuffling and re-organising them until group consensus was reached.

\section{Closing phase}

Thanks, and appreciation was expressed to the participants for taking part and sharing their experiences.

\section{RESULTS AND DISCUSSION}

The findings are discussed under the three activities (Van Wyngaarden 2017, 229).

\section{Activity 1: Questions}

The major findings for activity 1 are addressed under professional and personal relevance, and how the action research process changed educational practices.

Professional: The participants described their involvement in the action research study as a "journey towards excellence". Participants viewed action research as an "excellent methodology" which forced them "to reflect on their own values, beliefs and practices". Saadet $(2014,43)$ similarly pointed out that teacher participants in their action research study were encouraged to reshape their knowledge, reflect on their teaching practices and question their previously held beliefs, attitudes and assumptions. In this study, participants described the action research methodology as a "fresh approach" that encouraged group engagement and cohesion. The participants also felt that the action research study produced a comprehensive action plan which addressed nurse educator challenges. Dickinson et al. $(2005,274)$ found that action research enables practitioners and researchers to collaborate in order to improve practice. In this study, participants explained how their involvement in the action research study accomplished professional growth and development. Saadet $(2014,31)$ maintains that action 
research can be used as a professional development model which involves educators inquiring, studying and reflecting into their own practice and improving their teaching practices.

In this study, the World Café gave the participants an opportunity to express that their knowledge improved due to "the sharing of practice wisdom and best practices with each other", resulting in improved educational practices. A direct result of the action research study was that nurse educators received professional development sessions from expert facilitators on various student-centred teaching and learning practices. Lim $(2015,3)$ and Hassen $(2016,6)$ show that action research can be an effective tool that enables teachers to develop professionally.

Personal: Participants explained that participating in the action research study resulted in the self-evaluation and reflection of their own teaching practices which encouraged them to use more student-centred teaching and learning practices. In addition, the participants said that the action research study was "professionally conducted and stimulated their reasoning skills". Furthermore, the action research study "was motivating and it enhanced communication skills, interpersonal relationships and self-confidence". Participants felt that they "developed improved patience, tolerance and constructive criticism skills". Participants felt that their involvement in the action research study ignited a "passion for nursing education and encouraged further studies".

Changed educational practices: The participants explained that the action research study "inspired them to use more student-centred teaching and learning practices" which may encourage clinical reasoning and critical thinking skills in their students. Participants from a study conducted by Cabaroglu $(2014,84)$ unanimously reported that action research led to enhanced autonomy, creativity, reflectivity and confidence building. A particular theme that resonated throughout the study was an improvement in teacher's problem-solving skills, and as a result, in their teaching practices. In this study, participants pointed out that the action research study resulted in a "mind-set change from being a teacher to being a facilitator". Furthermore, the participants said that "theory and practice correlation was encouraged and made easier through critical thinking". Lastly participants realised the value of thinking and creativity in teaching and learning practices. Cabaroglu $(2014,84)$ indicated that being involved in action research promoted "reflective learning and deep thinking".

\section{Activity 2: Drawings}

The participants visually presented the relevance of the action research study in pictures that they drew. Their pictures illustrated that the action research study, in their own words "was a journey of not knowing to a journey of knowing". In their opinion there was movement from a 
dark space to light. They said that they experienced personal and, professional growth and improvement. Participants showed how they were able to celebrate their successes at the end of the action research study. The pictures portrayed the use of teamwork and collaboration throughout the action research study. Both groups used pictures to show that the action research study was a journey (Photo 2). Group 1 participants drew a bus driving on a bumpy road, showing a journey, that was bumpy at first, but that reached its destination. Group 2 participants drew a picture of runners running a relay race, where the team finished the race because of their participation and dedication as a team. These participants saw themselves "as a group of educators working together as a team using each other's strengths to reach mutual goals".
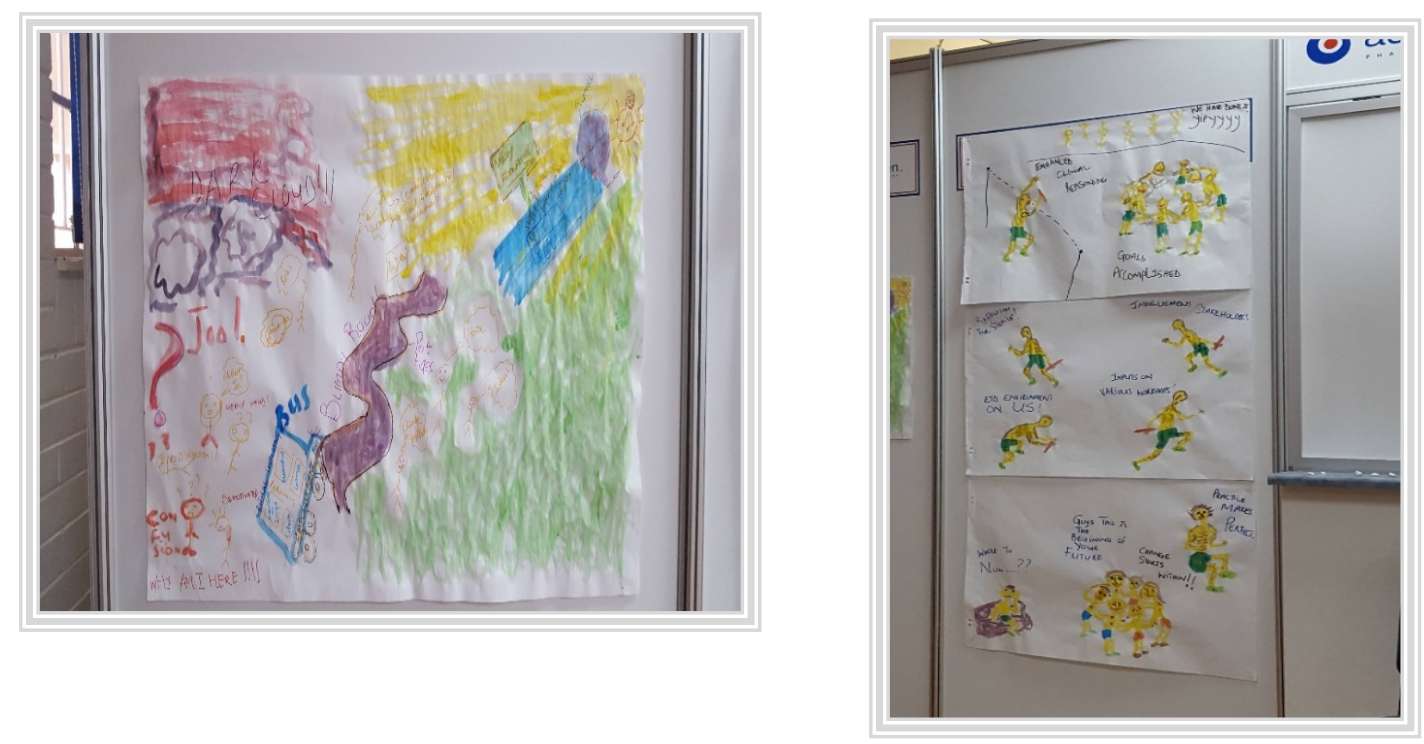

Photo 2: Drawing by group 1 on the left and group 2 on the right. Drawings were produced during the second activity, after answering questions. Each group was asked to draw one drawing. (Photos taken with consent of the participants)

\section{Activity 3: Words}

Participants identified statements and words to describe the action research study and clarify the relevance of the action research study. Teamwork stood out, with words such as "communication, sense of belonging", and so forth. Facilitation was highlighted as important and included words such as "motivation, enthusiasm, creativity and fun". "Reflection and selfawareness" stood out as the cornerstone of action research. Finally, the participants identified "accomplishment". They felt they had improved and advanced because of the action research study. They believe that "critical thinking and clinical reasoning" was one of their major accomplishments (view Figure 1). 


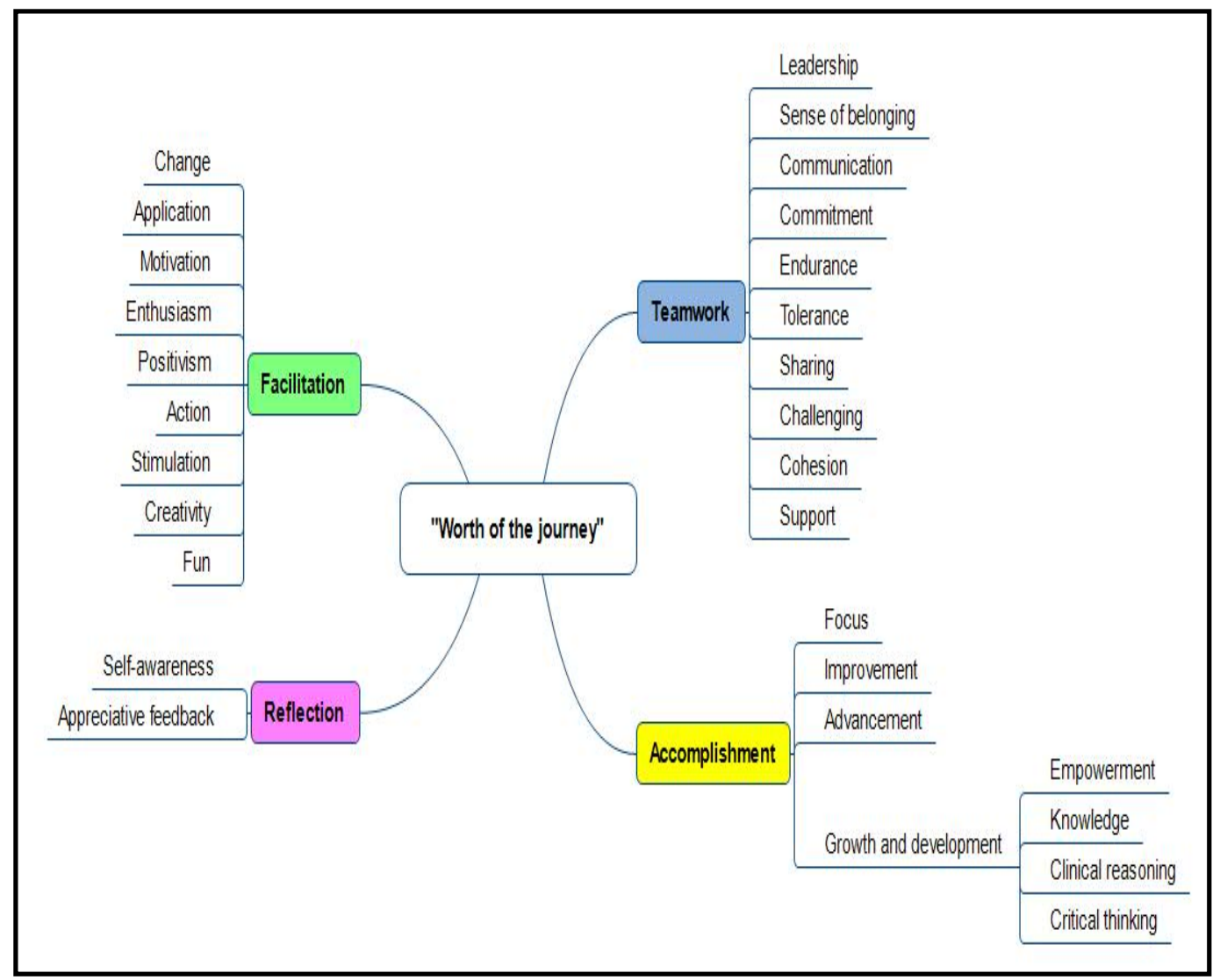

Figure 1: Schematic representation of the themes and categories. (The "words" were identified during activity three and all the members of the World Café participated in identifying themes).

Action research provided us with the opportunity and the means to improve teaching and learning practices by working with nurse educators collaboratively. This action research study managed to accomplish the purpose of action research, which according to Given $(2008,4)$ is to solve practical problems and facilitate change. We hope that findings from this study will be able to help those involved in nurse educator professional development to understand how action research can contribute to the professional development of nurse educators and encourage them to carry out action research with the aim of improving their teaching practices.

\section{CONCLUSION}

The World Café method proved to be an effective, creative, fun method to collect and analyse data. The method allows for real conversations around mutual topics of interest and the rich data collected is a true reflection of the participants' viewpoints and experiences. The participants fully participated in the data analysis therefore authenticating the findings, as this is a form of member checking. The World Café yielded meaningful data which demonstrated the value of action research as a methodology to improve nurse educators' teaching practices.

Action research was used by nurse educators to improve their own teaching practices and transform nursing education. In this study, we illustrated how the World Café was used to 
collect data to evaluate the "worth" of an action research study. The success of the data collection process was attributed to the common characteristics of the World Café method and action research. The World Café method can be used to collect data and as a teaching strategy to encourage students to engage in exploring various topics of interest whilst developing competencies in communication, building relationships and collaborative learning.

The action research study impacted on the professional development of nurse educators positively and offered various training sessions on student-centred teaching practices such as unfolding case studies, inquiry-based teaching, case-based teaching, clinical ward rounds and appreciative feedback. Nurse educators demonstrated an understanding of their teaching practices through reflection and used this learning to improve their own practices. Consequently, the action research study resulted in improved communication, team work, greater cohesion and collaboration amongst the nurse educators.

\section{ACKNOWLEDGEMENTS}

The National Research Foundation for part-time doctoral scholarship supported the study.

\section{REFERENCES}

Bland, A. R., E. K. Rossen, R. Bartlett, D. D. Kautz, T. Carnevale and S. Benfield. 2009. Implementation and testing of the OPT model as a teaching strategy in an undergraduate psychiatric nursing course. Nursing Education Perspectives 30 (1): 14-21.

Boomer, C. A. and B. McCormack. 2010. Creating the conditions for growth: A collaborative practice development programme for clinical nurse leaders. Journal of Nursing Management 18: 633-644.

Bradbury, H. 2015. The Sage handbook of action research. London: Sage Publications Ltd.

Brown, J. and D. Isaacs. 2005. Sharing our futures through conversations that matter. San Francisco: Berrett-Koehler Publishers Inc.

Cabaroglu, N. 2014. Professional development through action research: Impact on self-efficacy. System 44: 79-88.

Chabeli, M. M. 2010. Concept-mapping as a teaching method to facilitate critical thinking in nursing education: A literature review. Health SA Gesondheid 15(1): 1-7.

Chang, W. and S. Chen. 2015. The impact of World Café on entrepreneurial strategic planning capability. Journal of Business Research 68:1283-1290.

Chilemba, E. B. and J. C. Bruce. 2015. Teaching styles in Malawian BSN programmes: A survey of nurse educator preferences. Nurse Education Today 35(2): e55-e60.

Dawkins, V. and A. Solomons. 2017. Introducing the World Café to doctor of nursing practice students. Journal of Nursing Education 56(10): 639.

Dickinson, A., C. Welch, L. Ager and A. Costar. 2005. Hospital mealtimes: Action research for change? Nutrition Society 64: 269-275.

Ellis, D. M. 2016. The role of nurse educator's self-perception and beliefs in the use of learner-centered teaching in the classroom. Nurse Education in Practice 16(1): 66-70.

Fahlberg, B., E. Rice, R. Muehrer and D. Brey. 2014. Active learning environments in nursing: The experience of the University of Wisconsin-Madison School of Nursing. New Directions for 
Teaching and Learning 137: 85-94.

Farr, J. 2013. Shared listening: Using the World Café approach as a revision tool in a final year undergraduate programme. The Journal of Learning and Teaching at the University of Greenwich 8: paras. $1-21$.

Fouché, C. and G. Light. 2010. An invitation to dialogue, The World Café in social work. Qualitative Social Work 0(0): 1-22.

Froneman, K., E. du Plessis and M. P. Koen. 2016. Effective educator-student relationships in nursing education to strengthen nursing students' resilience. Curationis 39(1): 1-9.

Given, L. M. 2008. The SAGE encyclopedia of qualitative research methods 2 vols. London: Sage.

Hassen, R. 2016. Female teachers' professional development through action research practice. Journal of Education and Practice 7(22): 6-18.

Gilson, J. 2015. An exploration into inspiration in heritage interpretation through virtual World Café. (Dissertation). Canada: Royal Roads University.

Jordaan, J. 2016. Exploring first-years' demands from the perspectives of student support structures: A Word Café study. (Dissertation). South Africa: North West University.

Jorgensen, J. and F. Steier. 2013. Frames, framing and designed conversational processes: Lessons from the World café. The Journal of Applied Behavioral Science: 1-18.

Lim, T. 2015. Teacher professional development through action research: the case for a mathematics teacher. Open University Malaysia: 1-11.

McKee, S. E. and C. Billman. 2011. Andragogical methods applied to nursing education: Adult education for adult students. Midwest Research-to-Practice Conference in Adult, Continuing, Community and Extension Education, Lindenwood University, 21-23.

Partridge, M. 2015. Evaluation Café: A review of the literature concerning World Café methodology used as an evaluation tool in education. Innovative Practice in Higher Education. www. journals.staffs.ac.uk (Accessed 7 June 2016).

Preller, B., J. Affolderbach, C. Schulz, S. Fastenrath and B. Braun. 2014. Sustainability research and interactive knowledge generation: The Green Building Sector. GreenRegio Working Paper 1: 117. http://hdl.handle.net/10993/18720 (Accessed 20 August 2016).

Roos, V. and F. du Toit. 2014. Perceptions of effective relationships in an institutional care setting for older people. SA Journal of Industrial Psychology 40(1): 1-9.

Saadet, K. K. 2014. Professional development journey through action research: A case of a primary school teacher in an EFL context. The International Journal of Educational Researchers 5(2): 3046.

Shellenbarger, T. and M. Robb. 2015. Technology-based strategies for promoting clinical reasoning skills in nursing education. Nurse Educator 40(2): 79-82.

Slavich, G. M. and P. G. Zimbardo. 2012. Transformational teaching: Theoretical underpinnings, basic principles, and core methods. Educational Psychology Review 24(4): 569-608.

Stöckigt, B., M. Teut and C. M. Witt. 2013. CAM use and suggestions for medical care of senior citizens: A qualitative study using the World Café. Evidence-Based Complementary and Alternative Medicine: $1-8$.

Tan, S. and J. Brown. 2005. The World Café in Singapore creating a learning culture through dialogue. The Journal of Applied Behavioural Science 41(1): 83-90.

Van Wyngaarden, A. 2017. Educational practices for promoting student nurses' clinical reasoning skills. (Dissertation). South Africa: University of Pretoria.

World Café. 2016. World Café Method. www.theworldcafe.com (Accessed 6 December 2017). 